\title{
Contributing to a Healthy Older Population of the Future: Investigating the Daily Walking Steps of Working Adults in Hong Kong
}

\author{
Linda Y. K. Lee*, Simon C. Lam, S. L. Wong, Alisa K. P. Wong, Cheryl C. Y. Yeung \\ Division of Nursing and Health Studies, The Open University of Hong Kong, Hong Kong, China \\ Email: ${ }^{*}$ yklee@ouhk.edu.hk
}

Received 9 July 2015; accepted 10 September 2015; published 17 September 2015

\begin{abstract}
Developing a healthy lifestyle during adulthood is one of the essential factors to prepare for healthy aging. This cross-sectional descriptive study investigated the daily walking steps of 893 working adults from nine occupation categories in Hong Kong. Their daily walking steps were measured using a pedometer. Analysis of variance (ANOVA) was used to compare the difference in daily walking steps between participants in different occupation category. Chi-square test was used to compare the difference in proportion of working adults in each occupation category who walked and did not walk 10,000 steps per day. Results reveal that the participants in average walked 8661 steps per day. "Plant and machine operators and assemblers" and "clerks" were the two least active groups. Participants from the nine occupation categories demonstrated a significant difference in the number of daily walking steps. Post hoc analysis revealed a significant difference between "plant and machine operators and assemblers" and "service workers and shop sales workers" $(p<0.01)$, as well as between "plant and machine operators and assemblers" and "craft and related workers" $(p<0.01)$. Participants from the nine occupation categories also demonstrated a significant difference in the proportion of those who walked and did not walk 10,000 steps per day. Owing to a large difference in number of participants in the nine occupation categories and other study limitations, further systematic investigation is indicated to confirm the study results. To summarize, working adults in Hong Kong are only somewhat active. Identifying the factors that deter the working adults from walking and the ways to promote walking among working adults is necessary to prepare a healthy older population of the future.
\end{abstract}

\section{Keywords}

Pedometer, Physical Activity, Walking, Working Adults, Hong Kong

\section{Introduction}

People are encouraged to prepare for healthy aging in early adulthood because health-related behaviors are

\footnotetext{
${ }^{*}$ Corresponding author.
}

How to cite this paper: Lee, L.Y.K., Lam, S.C., Wong, S.L., Wong, A.K.P. and Yeung, C.C.Y. (2015) Contributing to a Healthy Older Population of the Future: Investigating the Daily Walking Steps of Working Adults in Hong Kong. Journal of Biosciences and Medicines, 3, 22-31. http://dx.doi.org/10.4236/jbm.2015.39004 
usually established during this stage [1]. Being physical active is essential for healthy aging while being physical inactive can lead to negative health consequences. Physical inactivity is the fourth leading risk factor for global mortality (6\%), followed by high blood pressure (13\%), tobacco use (9\%), and high blood glucose (6\%) [2]. Physical inactivity has implications on global health as it contributes to the prevalence of non-communicable diseases, such as cardiovascular disease, diabetes, and cancer. It also contributes to the prevalence of related risk factors, including high blood pressure, high blood sugar, and overweight [2]. Physical inactivity is estimated to contribute to about $21 \%$ to $25 \%$ of breast and colon cancer risk, $27 \%$ of diabetes, and about $30 \%$ of ischemic heart disease risk [3].

Physical inactivity is a public health epidemic. In the United States, approximately 25\% of American adults do not perform any physical activity during their leisure time. The range varies from $10 \%$ to $43 \%$ across different states [4]. In 2012, the Behavioural Risk Factor Survey conducted in Hong Kong reported that about 62.2\% of the 2041 respondents (aged 18 - 64) do not engage in any vigorous physical activity for at least 10 minutes a day, about $50.1 \%$ do not engage in any moderate physical activity for at least 10 minutes a day, and about $19.2 \%$ of the respondents sit for at least 10 hours every day during weekdays. Approximately 37.9\% of the respondents perform exercise during their leisure time less than once a month. Overall, only 39.5\% of the respondents canreach the World Health Organization's recommended level of physical activity for adults aged 18 to 64 [5], which is to perform at least 150 minutes of moderate aerobic physical activity throughout the week, at least 75 minutes of vigorous aerobic physical activity throughout the week, or an equivalent combination of the above two types of physical activities. For general practice, 30 minutes of moderate exercise per day is recommended [2].

In response to the prevalence of physical inactivity and its undesirable health consequences, scholars suggest sedentary individuals to incorporate physical activity into their daily routine [6]. Among the various forms of physical activities, walking is the most recommended [7]. Walking is easy to perform. It is a viable and effective option for most ambulatory individuals. Increased walking can improve the overall health status of an individual and prevent the occurrence of numerous chronic health conditions, such as cardiovascular disease, diabetes mellitus, osteoporosis, and depression [8]-[10]. In view of the extensive health benefits that can be gained from walking, in 1960, a Japanese scholar recommended that healthy adults take 10,000 steps per day. This recommendation has been widely adopted across the world [8] [11] [12]. Although accumulating 10,000 steps per day does not necessarily mean that the recommended 30 minutes of moderate physical activity per day has been met, research reveals that those who walk 10,000 per day are more likely to meet the recommended amount of daily physical activity [13].

Walking is a common form of physical activity. For healthy adults, walking at speeds consistent with normal ambulation is equivalent to moderate physical activity [14]. Hence, the number of steps that an individual takes per day can be considered as an indicator of one's level of physical activity [15]. Nevertheless, the walking behavior of the Hong Kong population remains to be studied.

Hong Kong has a dense population. In mid-2015, 7.3 million people live in an area of $1092 \mathrm{~km}^{2}$ [16]. Living and working environment tends to be small. Moreover, Hong Kong is a fast-moving city. Hong Kong citizens lead a busy life in general. They work long hours a day [17]. The unique nature of the geography and lifestyle in Hong Kong may reveal aunique pattern of walking behavior among its population.

Among the Hong Kong population, working adults represent a unique group. In mid-2015, about 3.9 million working adults can be found in Hong Kong, accounting for 61.4\% of the local labour work force [18]. To the working adults, work occupies a significant portion of their time. Most of these adults have to work at least eight hours per day for at least 35 years (assuming that one's career falls between the ages of 20 and 55). Because of the difference in work nature, working adults in different occupation category may demonstrate different walking behavior. This is an area which has not been examined systematically. The Hong Kong government classifies occupations into nine categories based on their nature: 1) managers and administrators, 2) professionals, 3) associate professionals, 4) clerks, 5) service workers and shop sales worker, 6) craft and related workers, 7) plant and machine operators and assemblers, 8) elementary occupations, and 9) skilled agricultural and fishery workers [19]. Examples of each occupation category are provided in Table 1. An examination of the walking behavior of working adults in different occupation categories can address the current knowledge gap. Moreover, the findings can identify the less active groups and suggest specific health promotion work on those groups. By doing so, the working adults can develop a healthier lifestyle and have a higher chance to achieve healthy aging in the future. Thus, a study on the walking behavior of working adults in Hong Kong was conducted. 
Table 1. The nine occupation categories.

\begin{tabular}{|c|c|c|}
\hline & Occupation Category & Example \\
\hline 1) & Managers and administrators & $\begin{array}{ll}\text { legislators } \\
\text { senior government officials } \\
\text { directors and chief executives }\end{array}$ \\
\hline 2) & Professionals & $\begin{array}{ll}\text { lawyers } \\
\text { doctors } \\
\text { accountants }\end{array}$ \\
\hline 3) & Associate professionals & $\begin{array}{l}\text { technicians } \\
\text { medical assistants } \\
\text { inspectors }\end{array}$ \\
\hline 4) & Clerks & $\begin{array}{ll} & \text { secretaries } \\
\text { typists } \\
\text { data entry operators }\end{array}$ \\
\hline 5) & Service workers and shop sales workers & $\begin{array}{ll} & \text { waiters } \\
& \text { hairdressers } \\
& \text { salespersons }\end{array}$ \\
\hline 6) & Craft and related workers & $\begin{array}{ll} & \text { carpenters } \\
\text { shoe-makers } \\
\text { tailors }\end{array}$ \\
\hline 7) & Plant and machine operators and assemblers & $\begin{array}{ll}\text { papermaking-plant operators } \\
\text { shoemaking-machine operators } \\
\text { electronic-equipment assemblers }\end{array}$ \\
\hline 8) & Elementary occupations & $\begin{array}{l}\text { domestic helpers } \\
\text { messengers } \\
\text { garbage collectors }\end{array}$ \\
\hline 9) & Skilled agricultural and fishery workers & $\begin{array}{ll} & \text { gardeners } \\
\text { farmers } \\
\text { aquatic life cultivation workers }\end{array}$ \\
\hline
\end{tabular}

\section{Methods}

\subsection{Aim and Objectives}

This cross-sectional descriptive study aimed to examine the daily walking steps of working adults in Hong Kong. The three objectives were: 1 ) to examine the daily walking steps of working adults in different occupation categories, 2) to compare the difference in daily walking steps of working adults in different occupation categories, and 3) to compare the difference in proportion of working adults in different occupation categories who walk and do not walk 10,000 steps per day.

\subsection{Sample}

Quota sampling, a method wherein researchers identify strata comprising mutually exclusive homogeneous subsets from the population and then conveniently recruits participants from each stratum, was performed in the selection of participants. This sampling method guarantees that diverse segments are adequately represented and demonstrates an improvement over convenience sampling in quantitative studies. Quota sampling is a relatively easy way to improve the representativeness of a non-probability sample [20]. Nine strata were formed according to the occupation categories adopted by the Hong Kong government in the statistics report [19]. The strata included: 1) managers and administrators, 2) professionals, 3) associate professionals, 4) clerks, 5) service workers and shop sales workers, 6) craft and related workers, 7) plant and machine operators and assemblers, 8) elementary occupations, and 9) skilled agricultural and fishery workers. Working adults were recruited from every stratum. The inclusion criteria were as follows: a) aged 18 - 64 years, b) with a full-time job, and c) being ambulatory.

\subsection{Data Collection}

Daily walking steps were recorded using a pedometer. It is a small and portable electronic device that is worn at the waist and counts the steps taken by a person by detecting the waist motion. Using a pedometer is a practical 
and valid method for daily assessment of walking steps under free living conditions for research purposes [21]-[23]. In the present study, the Omron HJ-113 model was used. This instrument measures the daily step count and has a seven-day memory. It is valid for measuring step counts because its results demonstrate a strong correlation with those of an accelerometer [24] and a hand counter [25]. In research, pedometer is commonly used for three purposes, namely, providing feedback to participants on their walking performance, motivating participants to walk more by showing immediate feedback on their progress, and recording the participants' walking performance. Considering that only the last purpose was relevant to the present study, researchers sealed the screen of the pedometer with opaque adhesive tape and prevented the participants from knowing the number of their steps, which might affect their walking performance. Instructions related to the use of the pedometer were given to the participants. Participants were instructed to carry the pedometer at their waist for seven consecutive days, except while swimming, bathing, and sleeping. Their dailysteps were recorded by the pedometer. After the period of data collection, the researcher collected the pedometer from individual participant and retrieved the data from the pedometer.

Demographic information, including age, gender, education level, and occupation nature, was obtained through a questionnaire. Finally, information on the number of day(s) in which the participants failed to carry the pedometer or when they had a holiday was likewise recorded on a daily log.

\subsection{Data Analysis}

The daily walking steps of the participants were calculated with reference to the following three principles. First, data should be collected on the day in which the participant was carrying the pedometer. In case the participant failed to carry the pedometer, the completeness of the data could not be guaranteed. Second, data should be collected on a working day as data collected on a holiday would not reflect the walking performance of the working adults during a regular day in their occupation. Third, data should be collected from at least three regular working days and the average step count obtained. A previous study on pedometer-determined physical activity demonstrated that, for adult participants, the data collected in three days were adequate to provide a reasonable estimation of the participant's daily performance [26]. In case a participant produced complete data on more than three working days, data from three randomly selected working days were used for data analysis.

Data were analyzed using the software Statistical Package for Social Sciences (version 19). Before data analysis, data were manually checked for accuracy. Input error was identified and corrected. Data were also assessed for normality using normal probability plot. All variables were found to be normally distributed. Descriptive statistics were used to summarize the characteristics of the participants and the number of their daily walking steps. Analysis of variance was employed to compare the difference in daily walking steps between participants in different occupation categories. Games-Howell test, as a post hoc test, was performed to determine pairwise differences. Chi-square test was used to compare the difference in the proportion of working adults in different occupation categories who walked and did not walk 10,000 steps per day. The significance level was set at $p<$ 0.05 .

\subsection{Ethical Considerations}

Ethical approval was obtained from the President's Advisory Committee on Research and Development of the university with which the authors were affiliated. Ethical considerations were guided by the Declaration of Helsinki of the World Medical Association, which is the international ethical standard for human protection. Potential participants were approached and invited to participate in the study. They were provided with information regarding the purpose and procedures of the study and were assured of the confidentiality and anonymity in the use of data. Individuals who agreed to participate signed a consent form.

\section{Results}

A total of 913 participants were recruited, among which 893 participants (97.8\%) completed the study by generating data for at least three working days. No significant difference in background characteristics was found between the participants who completed the study and those who did not.

\subsection{Characteristics of Participants}

The mean age of the participants was 35.8 years (range $=19$ to 64$)$. Half of them were male $(n=455 ; 51.0 \%)$. 
More than half of the participants ( $\mathrm{n}=559 ; 62.6 \%$ ) had either reached or surpassed tertiary level. Table 2 shows the number of participants from each occupation category. To summarize, the "associate professionals" belonged to the largest group with 226 participants (25.3\%) and the "skilled agricultural and fishery workers" comprised the smallest group with 6 participants $(0.7 \%)$.

\subsection{Daily Walking Steps}

On average, the participants walked 8661 steps per day (male $=8992$ steps; female $=8317$ steps). Among them, 602 participants (71.8\%) did not achieve 10,000 steps per day. The "craft and related workers" represented the most active group, with the participants walked 9,676 steps per day. In contrast, the "plant and machine operators and assemblers" represented the least active group, walking only 6879 steps per day. One-way analysis of variance revealed a significant difference in daily walking steps of the participants in the nine occupation categories $(p<0.001)$. Post hoc analysis was performed using the Games-Howell test because the data did not meet the homogeneity of variances assumption [27]. Results revealed a significant difference between "plant and machine operators and assemblers" and "service workers and shop sales workers" $(p<0.01)$, as well as between "plant and machine operators and assemblers" and "craft and related workers" $(p<0.01)$ (Table 3). Chi-square test revealed a significant difference in the proportion of working adults in different occupation categories who walked 10,000 steps per day and those who did not walk 10,000 steps per day $(p=0.001)$ (Table 3).

\section{Discussion}

\subsection{Overall Performance}

Walking is the most common form of physical activity among the Hong Kong population [5]. On average, the

Table 2. Participants' characteristics $(\mathrm{N}=893)$.

\begin{tabular}{|c|c|c|}
\hline Characteristic & Mean & $\mathrm{SD}$ \\
\hline Age & 35.8 & 9.7 \\
\hline \multirow[t]{2}{*}{ Daily walking steps } & 8661 & 2270 \\
\hline & $\mathrm{n}$ & $\%$ \\
\hline \multicolumn{3}{|l|}{ Gender } \\
\hline Male & 455 & 51.0 \\
\hline Female & 438 & 49.0 \\
\hline \multicolumn{3}{|l|}{ Education level } \\
\hline$\leq$ Primary level & 81 & 9.1 \\
\hline Secondary level & 253 & 28.3 \\
\hline$\geq$ Tertiary level & 559 & 62.6 \\
\hline \multicolumn{3}{|l|}{ Occupation } \\
\hline Managers and administrators & 46 & 5.2 \\
\hline Professionals & 136 & 15.2 \\
\hline Associate professionals & 226 & 25.3 \\
\hline Clerks & 150 & 16.8 \\
\hline Service workers and shop sales workers & 192 & 21.5 \\
\hline Craft and related workers & 54 & 6.0 \\
\hline Plant and machine operators and assemblers & 25 & 2.8 \\
\hline Elementary occupations & 58 & 6.5 \\
\hline Skilled agricultural and fishery workers & 6 & 0.7 \\
\hline
\end{tabular}


Table 3. Participants’ performance by occupation category $(\mathrm{N}=893)$.

\begin{tabular}{|c|c|c|c|c|c|c|c|c|}
\hline \multirow[t]{2}{*}{ Occupation } & \multicolumn{4}{|c|}{$\begin{array}{c}\text { Steps/day } \\
\text { (on working days) }\end{array}$} & \multirow{2}{*}{$\begin{array}{c}\text { Walked } \\
\geq 10,000 \\
\text { steps/day } \\
\mathrm{n}\end{array}$} & \multirow{2}{*}{$\begin{array}{c}\text { Walked } \\
<10,000 \\
\text { steps/day } \\
\mathrm{n}\end{array}$} & \multirow[b]{2}{*}{$x^{2}$} & \multirow[b]{2}{*}{$p$} \\
\hline & Mean & SD & $F^{a}$ & $p$ & & & & \\
\hline Managers and administrators & 8339 & 2288 & 5.896 & $<0.001$ & 11 & 35 & 25.7 & 0.001 \\
\hline Professionals & 8431 & 2288 & & & 30 & 106 & & \\
\hline Associate professionals & 8528 & 2312 & & & 56 & 170 & & \\
\hline Clerks & 7947 & 2204 & & & 27 & 123 & & \\
\hline Service workers and shop sales workers & 9379 & 2960 & & & 68 & 124 & & \\
\hline Craft and related workers & 9676 & 3170 & & & 20 & 34 & & \\
\hline Plant and machine operators and assemblers & 6879 & 2475 & & & 2 & 23 & & \\
\hline Elementary occupations & 9156 & 3078 & & & 21 & 37 & & \\
\hline Skilled agricultural and fishery workers & 9675 & 4098 & & & 2 & 4 & & \\
\hline
\end{tabular}

${ }^{a}$ Post hoc analysis using the Games-Howell test revealed a significant difference between "plant and machine operators and assemblers" and "service workers and shop sales workers" $(p<0.01)$, as well as between "plant and machine operators and assemblers" and "craft and related workers" $(p$ $<0.01)$.

participants in this study walked 8661 steps per day (male $=8992$ steps; female $=8317$ steps). With reference to the three levels of physical activity which are defined as "inactive" ( $<6000$ steps per day), "somewhat active" (6000 to 9999 steps per day), and "regularly active" ( $\geq 10,000$ steps per day) [28], our participants were considered as somewhat active. Their performance was similar to that of adults from developed countries, such as Japan (male $=8763$ steps; female $=8242$ steps) [29] and the US (male $=8548$ steps; female $=7494$ steps) [30] . About $73.5 \%$ of the participants in the present study were unable to achieve the international recommendation of completing 10,000 steps per day.

Although the results reflected the level of physical activity of working adults during working days, it provided insight on the overall level of physical activity of the working adults. According to the generalization theory, individuals transfer their occupational practice to their free-time practice [31]. Thus, individuals with an active occupational practice adopt active free-time practice. Conversely, individuals with less active occupational practice adopt less active free-time practice. Our participants who had a somewhat active occupational practice were most likely to adopt a somewhat active lifestyle during their leisure time. In fact, achieving 10,000 steps per day is not difficult for working adults. With regard to the estimation that 30 minutes of brisk walking is equivalent to 3000 to 3500 steps [32], adding 30 minutes of brisk walking into daily life can aid the majority of working adults in reaching 10,000 steps.

\subsection{The Least Active Occupation Categories}

In terms of daily number of steps, the least active occupation category was "plant and machine operators and assemblers" (daily steps $=6879$ ). Workers in this category are required to operate either a large or a small machine in a fixed location for a long period of time. Such work discourages moving around and walking. Findings further revealed significant difference in daily walking steps between working adults in "plant and machine operators and assemblers" and those in another two occupation categories. As the number of participants in this occupation category was only 25 , its ability to reveal group difference was weakened. Therefore, further study with a larger sample size is indicated to confirm the findings.

The second least active occupation category was "clerks" (daily steps $=7947$ ). Primarily stationed in an office, clerks are mainly responsible for handling general office tasks, such as record keeping and filing, answering inquiries, and preparing documents. In Hong Kong, clerks are more commonly regarded to have a low level of physical activity [33]. A previous study on working adults with sedentary jobs (e.g., clerical, administrative, or data processing) reported that participants walked 7029 steps per day [34].

The present preliminary results indicated a significant difference existed in the proportion of working adults 
in different occupation categories who walked 10,000 steps per day and those who did not walked 10,000 steps per day. Owing to a large difference in number of participants in the nine occupation categories (from 6 to 226) and without a well-matched non-working group for comparison, it is too early to ascertain the influence of occupation on walking behavior among working adults. More systematic investigation is indicated to confirm the study findings.

Individuals holding sedentary jobs may have a higher risk of health problems because about half of their waking time is committed to their sedentary job and only a minimal amount of time is left for physical activity [34]. Therefore, considerable effort should be paid to promote walking in the workplace.

\subsection{Health Promotion in the Workplace}

The results provided a better understanding of the walking behavior of working adults in Hong Kong. Overall, the working adults in Hong Kong were only somewhat active. The walking performance of working adults in different occupation categories was revealed, and the relatively inactive groups were identified. Promoting physical activity in the workplace is strongly suggested. In fact, providing health promotion in the workplace has several advantages. First, it can reach a large number of people with similar characteristics and needs at the same time. Second, it can reach staff members who do not participate in the conventional health promotion activities offered by health organizations. Third, it can bring positive results to the workplace, for a healthy staff is a productive staff. A group of healthy staff can translate several benefits to the workplace, such as reduced absenteeism, reduced accident rate, improved efficacy, increased staff retention, and high morale. Fourth, the benefits can reach beyond the individual staff because they may influence their family and friends to modify their behavior as well [35].

Several measures can be initiated to promote walking in the workplace. In terms of the environment, designing new buildings with walking trails, stairwells, and open spaces can promote walking and the use of stairs. In terms of policy, suspending part of the elevator service during non-busy hours can encourage the use of stairs, and supporting flexible physical activity time within the working hours can aid the staff to increase their level of physical activity. In terms of operations, conducting health education programs can enhance the understanding of the benefits of walking among the staff. The idea of walking 10,000 steps per day can provide a useful and achievable target for the staff in modifying their behavior. The provision of practical tips on walking can also facilitate the development of an active lifestyle. Finally, offering a free pedometer can aid the staff in monitoring their own level of walking and motivate them to increase walking. Although health promotion activities aim to promote the importance of being physically active and support behavioral change, identifying the barriers to walking and devising measures to overcome these barriers are equally necessary.

\subsection{Strengths and Limitations of the Study}

This study was conducted with the participation of about 900 working adults in Hong Kong. The study had a wide coverage of various occupations. Significant characteristics of the study sample, such as occupation and education level, were comparable to those of the Hong Kong population [16]. As such, the sample could be considered as representative. This study adopted an objective and accurate way to measure walking steps. A pedometer was used to record walking instead of asking participants to measure their own steps using paper and pencil. Moreover, sealing the screen of the pedometer further reduced the effect of motivation on the participants who might otherwise increase their walking steps.

Nevertheless, the use of non-probability sampling might have induced selection bias. The outcome might have been affected, as it is common for research on physical activity to recruit people who are already active [35]. The Hawthorn effect might also have been in play; that is, knowing that they were being studied might have affected the behavior of participants, influencing them to work toward the desired direction [36]. Therefore, the reality might have been underestimated. Likewise, the uneven number of participants in each occupation category limited the capacity of the study to detect the difference between categories. Despite the original intention to recruit an equal number of participants from each occupation category, the researchers faced the predicament that some of the occupations, such as "skilled agricultural and fishery workers" and "plant and machine operators and assemblers", had been reduced in size over the past decades. Hence, in the future, contacting the unions of the respective occupations is recommended in order to gain access to its members, thereby boosting the sample size and increasing the strength of group comparison. With better access to the members in each oc- 
cupation category, the chance of conducting probability sampling may likewise be increased.

\subsection{Recommendations}

This study measured the number of steps and did not specifically take exercise intensity into consideration. If this issue was to be addressed, the participants would have had to carry additional instruments, such as a heart rate monitor and accelerator. However, those instruments would be strong external motivators and would affect the performance of the participants. Therefore, the present study did not consider this approach. In the future, more studies with thoughtful arrangement may be designed to shed light on the intensity of walking in working adults.

In this study, walking was the only physical activity examined, and the step count provided a useful index of the ambulatory activity level of working adults. However, this study did not consider other physical activities that primarily involve arm movements, such as carrying or pushing heavy objects. In fact, these types of physical activities are predominant in some of the occupations. To obtain a complete picture of the physical activity that the working adults engage in, comprehensive investigation may be conducted in the future.

\section{Conclusion}

Physical inactivity represents a public health epidemic with serious consequences. Thus, promotion of physical activity is an important topic in public health. Physical activity builds on a foundation of daily activities, such as walking, and then extends to volitional exercise and sport activities. Hence, promotion of walking represents a crucial and initial step toward the improvement of our citizens' health which will have positive impact on their healthy aging. The present study reveals that working adults in Hong Kong are somewhat active. "Plant and machine operators and assemblers" and "clerks" are identified as the two least active occupational groups. Future studies are indicated to further strengthen the research design and assess the level of physical activity of the working adults comprehensively. Moreover, identifying the factors that deter working adults from walking and investigating ways to overcome these barriers are important areas to consider.

\section{Acknowledgements}

This study was funded by The Open University of Hong Kong (R\&D 09/1.1). The authors are grateful tothe working adults for their participation.

\section{References}

[1] Sanders, K. (2006) Developing Practice for Healthy Ageing. Nurs Older People, 18, 18-21. http://dx.doi.org/10.7748/nop2006.04.18.3.18.c2417

[2] World Health Organization (2010) Global Recommendations on Physical Activity for Health. http://whqlibdoc.who.int/publications/2010/9789241599979_eng.pdf

[3] World Health Organization (2009) Global Health Risks: Mortality and Burden of Disease Attributable to Selected Major Risks. http://www.who.int/healthinfo/global_burden_disease/GlobalHealthRisks_report_full.pdf

[4] Centres for Disease Control and Prevention (2008) Facts about County-Level Estimates of Leisure-Time Physical Activity. http://www.cdc.gov/diabetes/pubs/factsheets/county_inactivity_estimates.htm

[5] Department of Health (2013) Behavioural Risk Factor Survey (April 2012)—Main Report. http://www.chp.gov.hk/files/pdf/brfs 2012apr summary en.pdf

[6] Dunn, A.L., Marcus, B.H., Kampert, J.B., Garcia, M.E., Kohl, H.W. and Blair, S.N. (1997) Reduction in Cardiovascular Disease Risk Factors: 6-Month Results from Project Active. Prev Med, 26, 883-892. http://dx.doi.org/10.1006/pmed.1997.0218

[7] Van Wormer, J.J. (2004) Pedometers and Brief e-Counselling: Increasing Physical Activity for Overweight Adults. $J$ Appl Behav Anal, 37, 421-425. http://dx.doi.org/10.1901/jaba.2004.37-421

[8] Yamanouchi, K., Takashi, T., Chilada, K., Nishikawa, T., Ito, K., Shimizu, S., et al. (1995) Daily Walking Combined with Diet Therapy Is a Useful Means for Obese NIDDM Patients Not Only to Reduce Body Weight but also to Improve Insulin Sensitivity. Diabetes Care, 18, 775-778. http://dx.doi.org/10.2337/diacare.18.6.775

[9] Miller, T.D., Balady, G.J. and Fletcher, G.F. (1997) Exercise and Its Role in the Prevention and Rehabilitation of Cardiovascular Disease. Ann Behav Med, 19, 220-229. http://dx.doi.org/10.1007/BF02892287 
[10] Alevizos, A., Lentzas, J., Kokkoris, S., Mariolis, A. and Korantzopoulos, P. (2005) Physical Activity and Stroke Risk. Int J ClinPract, 59, 922-930. http://dx.doi.org/10.1111/j.1742-1241.2005.00536.x

[11] Tudor-Locke, C. and Bassett Jr., D.R. (2004) How Many Steps/Day Are Enough? Preliminary Pedometer Indices for Public Health. Sports Med, 34, 1-8. http://dx.doi.org/10.2165/00007256-200434010-00001

[12] World Health Organization (2008) Preventing Non Communicable Diseases in the Workplace through Diet and Physical Activity. WHO/World Economic Forum Report of a Joint Event. World Health Organization, Geneva.

[13] LeMasurier, G.C., Sidman, C.L. and Corbin, C.B. (2003) Accumulating 10,000 Steps: Does This Meet Current Physical Activity Guidelines? Res Q Exerc Sport, 74, 389-394. http://dx.doi.org/10.1080/02701367.2003.10609109

[14] Ainsworth, B.E., Haskell, W.L., Whitt, M.C., Irwin, M.L., Swartz, A.M., Strath, S.J., et al. (2000) Compendium of Physical Activities: An Update of Activity Codes and MET Intensity. MedSciSports Exerc, 32, S498-S516. http://dx.doi.org/10.1097/00005768-200009001-00009

[15] Jordan, A.N., Jurca, G.M., Tudor-Locke, C., Church, T.S. and Blair, S.N. (2005) Pedometer Indices for Weekly Physical Activity Recommendations in Postmenopausal Women. Med Sci SportsExerc, 37, 1627-1632. http://dx.doi.org/10.1249/01.mss.0000177455.58960.aa

[16] Census and Statistics Department (2015) Hong Kong Statistics: Population. http://www.censtatd.gov.hk/hkstat/sub/so20.jsp

[17] Lee, L.Y.K. and Fan, R.Y.K. (2014) Beliefs and Practices of Chinese Adults in Hong Kong toward Preparation for Healthy Ageing: A Qualitative Study. Asian J Gerontol Geriatr, 9, 61-66.

[18] Census and Statistics Department (2015) Hong Kong Statistics: Labour Force. http://www.censtatd.gov.hk/hkstat/sub/so30.jsp

[19] Census and Statistics Department (2014) Hong Kong Statistics. http://www.censtatd.gov.hk/hong_kong_statistics/statistical_tables/index.jsp?subjectID=2\&tableID=013

[20] Polit, D.F. and Beck, C.T. (2013) Essentials of Nursing Research: Appraising Evidence for Nursing Practice. 8th Edition, Lippicnott, Philadelphia.

[21] Tudor-Locke, C. and Meyers, A.M. (2001) Methodological Considerations for Researchers and Practitioners Using Pedometers to Measure Physical (Ambulatory) Activity. Res Q ExercSport, 72, 1-12. http://dx.doi.org/10.1080/02701367.2001.10608926

[22] De Cocker, K., De Bourdeaudhuij, I. and Cardon, G. (2009) What Do Pedometer Counts Represent? A Comparison between Pedometer Data and Data from Four Different Questionnaires. Public Health Nutr, 12, 74-81. http://dx.doi.org/10.1017/S1368980008001973

[23] Lam, S.C., Lee, L.Y.K., Wong, S.L. and Wong, A.K.P. (2012) Pedometer-Determined Physical Activity and Body Composition in Chinese Working Adults. J Nurs Scholarsh, 44, 205-214. http://dx.doi.org/10.1111/j.1547-5069.2012.01460.x

[24] Sugden, J.A., Sniehotta, F.F., Donnan, P.T., Boyle, P., Johnson, D.W. and McMurdo, M.E.T. (2008) The Feasibility of Using Pedometers and Brief Advice to Increase Activity in Sedentary Older Women-A Pilot Study. BMC Health Serv Res. http://www.biomedcentral.com/1472-6963/8/169

[25] Giannakidou, D.M., Kambas, A., Ageloussis, N., Fatouros, I., Christoforidis, C., Venetsanou, F., et al. (2102) The Validity of Two Omron Pedometers during Treadmill Walking Is Speed Dependent. Eur J Appl Physiol, 112, 49-57. http://dx.doi.org/10.1007/s00421-011-1951-y

[26] Tudor-Locke, C., Burkett, L., Reis, J.P., Ainsworth, B.E., Macera, C.A. and Wilson, D.K. (2004) How Many Days of Pedometer Monitoring Predict Weekly Physical Activity in Adults? Prev Med, 40, 293-298. http://dx.doi.org/10.1016/j.ypmed.2004.06.003

[27] Field, A. (2007) Discovering Statistics Using SPSS. SAGE, London.

[28] Thompson, D.L., Rakow, J. and Perdue, S.M. (2004) Relationship between Accumulated Walking and Body Composition in Middle-aged Women. MedSciSports Exerc, 36, 911-914. http://dx.doi.org/10.1249/01.MSS.0000126787.14165.B3

[29] Inoue, S., Ohya, Y., Odagiri, Y., Takamiya, T., Suijo, K., Kamada, M., et al. (2011) Sociodemographic Determinants of Pedometer-Determined Physical Activity among Japanese Adults. Am J Prev Med, 40, 566-571. http://dx.doi.org/10.1016/j.amepre.2010.12.023

[30] Tudor-Locke, C., Bassett Jr., D.R., Rytherford, W.J., Ainsworth, B.E., Chan, C.B., Croteau, K., et al. (2008) BMI-Referenced Cut-Off Points for Pedometer-Determined Steps per Day in Adults. J Phys Act Health, 5, 126-139.

[31] Kirkcaldy, B.D. and Furnham, A. (1990) Personality and Sex Differences in Recreational Choices. Sportwissenschaft, 20, 43-55.

[32] Tudor-Locke, C., Ainsworth, B. and Whitt, M. (2001) The Relationship between Pedometer-determined Ambulatory 
Activity and Body Composition Variables. Int J Obes Relat Metab Disord, 25, 1571-1578. http://dx.doi.org/10.1038/sj.ijo.0801783

[33] Department of Health (2010) Action Plan to Promote Healthy Diet and Physical Activity Participation in Hong Kong. http://www.change4health.gov.hk/filemanager/common/image/strategic_framework/action_plan/action_plan_e.pdf

[34] Chan, C.B., Ryan, D.A.J. and Tudor-Locke, C. (2004) Health Benefits of a Pedometer-based Physical Activity Intervention in Sedentary Workers. Prev Med, 39, 1215-1222. http://dx.doi.org/10.1016/j.ypmed.2004.04.053

[35] Thomas, L. and Williams, M. (2006) Promoting Physical Activity in the Workplace: Using Pedometers to Increase Daily Activity Levels. Health Promot J Austr, 17, 97-102.

[36] Spence, J., Burgess, J., Rodgers, W. and Murray, T. (2009) Effect of Pretesting on Intentions and Behaviour: A Pedometer and Walking Intervention. Psychol Health, 24, 777-789. http://dx.doi.org/10.1080/08870440801989938 